\title{
Too sick or not too sick?
}

\section{The importance of stress and satisfaction with supervisor support on the prevalence of sickness presenteeism}

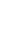

Abstract
In a sample of 3274 full-time Belgian workers, this article found that $62 \%$ of workers went to
work while being sick (sickness presenteeism) at least once over the past 12 months. Of all
workers who did not show sickness presenteeism themselves, another 6 out of 10 saw or heard
about sickness presenteeism in their own organization. This turns sickness presenteeism into
an important physical and mental health risk, demanding new policy measures from
organizational and governmental decision makers. Women were more likely to report
sickness presenteeism than men and junior workers were more prone to sickness
presenteeism than senior workers. Education did not explain the choice for sickness
presenteeism. Satisfaction with the supervisor had a direct negative effect on sickness
presenteeism. Finally, indirect effects were found between satisfaction with the supervisor
and sickness presenteeism via the prevalence of stress. While previous studies showed that
good supervisor support could make sick workers more productive when they show up at
work anyway, this study shows that good supervisor support lowers the probability that sick
workers turn up at work at all.

\section{Introduction}

Sickness absenteeism (SA) has been the subject of academic research for almost a century, for various obvious reasons. Not only is sickness an important risk for an individual's overall health and often increasing the medical costs incurred by governments, the fact of not being able to work also brings a cost for employers in terms of productivity losses and increased expenses (e.g., hiring a temporary replacement). SA may also put stress on the healthy coworkers when temporary replacements cannot be found or are less productive than the absent worker, forcing the healthy staff to work harder to obtain the same overall level of productivity. When these pressures occur regularly, overworked staff may become prone to SA themselves, starting a negative spiral. In recent years, however, research has also started to focus on the opposite side of the spectrum: Sickness presenteeism (SP) or showing up at work sick. Although sick workers do come to work, their presence may also have negative effects on the organization. They may e.g., work more slowly or require more breaks for the same wage, and may make more mistakes which turn out costly for the organization [1]. By not taking the mandatory rest, sick workers may also prolong their recovery [2] or aggravate their condition [3], making productivity losses during SP bigger than those incurred by a short period of SA. Sick workers may also affect the health of their coworkers [4] and the lack of response by the organization and peer pressure may lead the latter workers to think SA is unfavorable, making them turn to SP as well [5]. In such cases, the productivity losses for the 
organization are being multiplied. A recent study by Nagata et al [6] in a Japanese sample, values the costs of SP at $\$ 3,055$ per person per year, or more than five times the cost of SA (\$520). Studies estimate the prevalence of SP between 47\% [7] and 73\% [8] depending on the particular (national and industry) sample, stressing the importance of the matter even more.

These risks, among others, have led both researchers and practitioners to argue that SP should be avoided at all cost. However, this point of view has recently become subject of debate. A systematic review by Skagen en and Collins [9] e.g., questioned some of the risks often associated with SP. Drawing on longitudinal research, they found limited evidence to suggest that SP decreases future physical health and future workability. Also, the effect on future mental health seems to be mixed, since the authors are both reporting studies that found an effect of SP on mental health $[10,11]$ and studies that did not [12]. Based on their findings, it seems that long-term effects of SP are less strong than its short-term effects in the form of future SA and decreased self-rated health [9]. While these effects are still highly important to individuals and organizations, Skagen and Collins [9] lower the perception of SP as a detrimental issue on the long term.

At the same time, a study by Zhou et al [13] argues that it may be more important to deal effectively with SP, rather than eliminating it. Their research analyzes the effects of supervisor support on the productivity of the sick worker, using role ambiguity as a mediator. They argue that whilst workers are sick, they still have a limited amount of energy to spend. Assuming they know to prioritize (something the supervisor can help them with), they may thus be able to perform their most relevant job responsibilities [13]. We find additional support for this line of thought in a recent study by Thun, Halsteinli and Lovseth [14] in 545 Norwegian physicians, in which half of the respondents claimed that $11 \%$ of their tasks could have been done by other hospital personnel. With unreasonable illegitimate tasks being associated with higher SP, there may be grounds to suspect that prioritizing and an appropriate (re)distribution of tasks by the supervisor can have positive effects on the work performances during SP. Second, sick workers may be limited in their cognitive, physical and psychological resources and, given their aim to prioritize, they may draw more on social support [15]. Again, there is an important role for the supervisor. Third, when sick workers experience psychological stress because of the effects of the illness on their performance [16] and whether their sacrifice will be appreciated by the organization, the supervisor could make them feel more confident. E.g., by letting them know their sickness will be taken into account when evaluating the performance and that the organization values their effort even when they underperform [13].

The research at hand builds on the Zhou et al [13] research by further studying the role of the supervisor in SP prevalence among workers. It extends the previous research in several ways. First, the study by Zhou et al [13] was conducted in Portugal, with 99 respondents from 1 company in a specific sector (IT) that was claimed to be highly oriented towards team work and faced difficulties with temporarily replacing sick workers. This combination ensured peer pressure and therefore a higher prevalence of SP. Our study of SP, on the other hand, focuses on another European country, namely Belgium, including 3,275 respondents from companies in 15 different sectors, across all ages and education levels. We thereby aim to obtain a more 
representative indicator of SP-prevalence and a more elaborate view on the role of the supervisor in explaining SP by workers. Second, besides obtaining an indicator of SP presented by the respondents themselves, we also ask those that did not do SP in the past year whether they noticed or heard about SP in their organization. This enables us to get a broader understanding of the environment the worker sees himself in. Third, the Zhou et al [13] study uses the Oldham and Cummings [17] scale with items like "my supervisor rewards me for good performance", ranging from strongly disagree to strongly agree on a 7-point Likertscale. However, we argue that the satisfaction with the support of the supervisor may be a better variable than merely asking the respondent whether the support is provided. Finally, we include new variables like perceived stress levels, financial constraints and satisfaction with different aspects of work and life to get a broader understanding of the respondents' mindsets.

We therefore formulate the following hypotheses for our research. First, we hypothesize that satisfaction with the supervisor is negatively related to SP, in line with [13]. The better the supervisor is leading and supporting the work team, the less we expect SP to occur. Second, workload has already been positively linked to SP by Biron et al [18]. When one considers the job to be more demanding, the belief may grow that one cannot remain absent even when feeling ill. We thus hypothesize that perceived work stress is positively related to SP. Besides these direct effects, we also hypothesize that perceived work stress will mediate the relationship between supervisor support and SP. Motivation theories have already marked the importance of clear goal setting for worker job satisfaction [19] and improper supervisor instructions and poor team management are found to create role ambiguity, the latter being associated to workers' perceptions of work stressors [20]. We thus hypothesize:

$H_{1}$ : Satisfaction with the supervisor is negatively related to SP

$\mathrm{H}_{2}$ : Perceived work stress is positively related to SP

H3: Perceived work stress mediates the relation between satisfaction with the supervisor and SP

Next, we hypothesize that women will report less SP compared to men. Previous studies have shown that women are on average more concerned with their health and having a healthy life style than men [21], making it more likely they would listen to their own body and prefer a day of rest over going to work sick. We also hypothesize that the effect of satisfaction with the supervisor on SP will be stronger for women than for men, based on Garcia-Cabrera [22]. These authors investigated the role of supervisor support in the relationship between familywork spillovers and well-being, and found that supervisor support was more important to women than to men. Our hypothesis are therefore:

\section{$H_{4 a}$ : Women report less SP compared to men}

\section{$H_{4 b:}$ Gender moderates the relationship between satisfaction with the supervisor and SP}

Similarly, we hypothesize that junior employees in the early stages of their career consider SA more as a risk to their promotion opportunities and career advancement than senior workers do. We thus expect junior workers to show more SP than senior workers do. Also, drawing 
on Blanchard [23], supervisor support is considered more important for junior workers for their work performances and individual growth than for senior workers, based on their familiarity with the job and levels of experience. We thus hypothesize:

\section{$H_{5 a}$ : Junior workers report more SP compared to senior workers}

$H_{5 b}$ : Age moderates the relationship between satisfaction with the supervisor and SP

We also expect that the level of education will be related to the prevalence of SP. Educational levels have been positively related to interest in maintaining a healthy life style. Also, workers with higher levels of education are found to have more employment opportunities, making them less dependent on one particular employer and therefore possibly less inclined to sacrifice health related issues for a financial gain. Our hypotheses is thus:

\section{H6: Higher educated workers will report less SP than lower educated workers}

Finally, we hypothesize that financial constraints will affect one's decision to do SP. Aronsson and Gustafsson [24] already argued that while everyone is virtually able to opt for SA or SP, these options are not always equal for all workers. Depending on how important the wage is for the family income, to some SP may be a necessity and SA a luxury they cannot afford. We therefore hypothesize that:

H7: Workers who are satisfied with their family budget/savings will report less SP

$H_{8}:$ Single workers will report higher levels of SP

\section{Method}

\subsection{Participants and procedures}

The data for this study were collected by sending out emails with an invitation to participate in the research to 85.000 Belgian email addresses. This list of email addresses contains the professional contacts of the authors and the email addresses of respondents participating in previous scientific research over the past ten years. The latter part of the list was obtained by more than fifty students gathering respondents for their master theses over the past decade, coming from all Belgian provinces and from various social backgrounds, providing a database not biased by geographical location or social class. The list only contains email addresses, without any supplementary information about the owner of the email address, based on privacy regulations. Although it was our aim to only invite full-time employed workers, we were therefore not able to know whether the receiver of the invitation would meet this inclusion restriction and were unable to calculate an accurate response rate. In order not to signal to the excluded respondents that their opinion did not matter, these respondents were invited to take part in related researches. Various questionnaires on different topics were developed for students, housewives, retired people, part-time workers, self-employed business owners, currently unemployed professionals and impaired persons. The data were collected in February 2017, using one initial invitation and one reminder a week later. Contacts were assured of the confidentiality of their responses and the voluntary nature of participation 
in this study. They were given the option to have their email address removed from the database (used by 13 contacts) and to receive the findings of the study before publication in popular media (used by 32 contacts). Contacts were provided with an email address they could use if they had questions or comments (used by 21 contacts). All questions were answered within 3 hours and there were no critical incidents reported. After closing the online questionnaire, 10.488 respondents had participated in the various studies, of which 3.759 were Belgian FTE's and 3.274 answered questions relating to SP (87\%). Table 1 summarizes the main characteristics of the sample. The invitation to participate in the research, the reminder and all questionnaires were administered in Dutch.

Table 1. Sample characteristics.

\begin{tabular}{|c|c|}
\hline Variable & Prevalence in percentages \\
\hline Gender & Men $(55.9 \%)$ - Women $(44.1 \%)$ \\
\hline Marital status & Single (14.6\%) - Relationship (29.3\%) - Married (56.1\%) \\
\hline Educational level & $\begin{array}{l}\text { Primary }(\underline{0} .8 \%) \text {, Secundary Secondary }(18.9 \%) \text {, Bachelor }(35.0 \%) \text {, } \\
\text { Master }(40.4 \%), \operatorname{PhD}(3.5 \%) \text {, Other }(1.4 \%)\end{array}$ \\
\hline Type of employment & $\begin{array}{l}\text { White-collar worker }(67.1 \%) \text {, Blue-collar worker }(5.0 \%) \text {, Civil } \\
\text { servant }(27.9 \%)\end{array}$ \\
\hline Sector of employment & 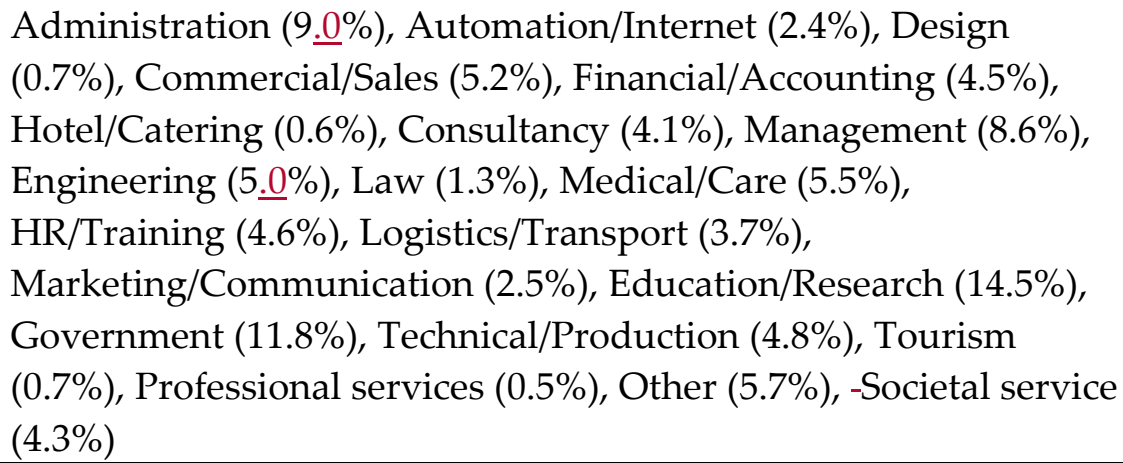 \\
\hline
\end{tabular}

\subsection{Measures}

\subsubsection{Sickness Presenteeism}

To measure SP, we offered respondents a short explanation of the concept in line with the Zhou et al [13,p.3380] definition referring to "employees attending work while sick". We then asked respondents whether they did this themselves over the past 12 months. This single item question, referring to at least one event over a recall period of 12 months, is in line with previous research [9]. We hereby also comply with McGregor et al [25], who argue that SP is better operationalized as a behavior than as a productivity loss stemming from attending work while sick. In the latter case, the correlation between the behavior and the outcomes of SP would present a greater risk of spurious correlation with other variables and create greater artificial inflation in effect sizes. We prevent such an effect by operationalizing SP as a behavior. 
Our operationalization, however, also implies that we measure actual SP and not the propensity of SP: It is possible that a respondent was not sick over the past 12 months and therefore was not confronted with the choice between SA and SP. While this measure reflects the actual prevalence of SP over the past 12 months, it may underestimate the potential SP that organizations could face (e.g., in case of a persistent flu epidemic).

Besides having done SP themselves, respondents were also given three other options. The first referred to not having done SP oneself, but having seen direct colleagues do SP over the past 12 months. The second referred to not having done SP oneself, but having heard that it had happened in their own company over the past 12 months. The third option referred to the situation in which the respondent did not do SP over the past 12 months and did not see or hear about it in their own organization. We thus offered a more varied choice than just the two extremes (having done PS or not), in order to avoid impressions of undervaluing the matter. Also, it may help to shed light on perceptions of peer pressure experienced by the workers.

\subsubsection{Stress on the job}

We measured stress on the job in two ways. First, using the single item "How often do you experience stress at work during the week?" and a 5-point Likert scale ranging from $1=$ never to 5 = always. Second, using the single item "How satisfied are you with the work pressure?" and a slider ranging from 0 to 10, with a half point interval (21 possible answers).

\subsubsection{Satisfaction with the supervisor}

Satisfaction with the supervisor was measured with 6 items, referring to satisfaction with different aspects of supervisor support: mutual understanding (1), division of tasks among team members (2), dealing with task problems in the team (3), dealing with feelings of team members (4), appreciation by the supervisor (5) and general supervisor satisfaction (6). A 21point Likert scale ranging from $0=$ very unsatisfied to $10=$ very satisfied was used. An exploratory factor analysis was performed to measure the underlying construct. All items loaded significantly, ranging from .87 to .90 , explaining $79 \%$ of the total variance of satisfaction with the supervisor. Hence, the latter was considered as factor in the analysis $(\alpha=.95)$.

\subsubsection{Satisfaction with various life aspects}

We used single item questions and sliders ranging from 0 to 10, with a half point interval. The introductory statement was "How satisfied are you with" followed by the next aspects: "your job in general", "pay (including benefits)", "the number of actual working hours", "the quality that you can deliver within the available time", "the number of vacation days", "your life in general", "your health", "your monthly family budget" and "your savings". 
224 A multi-group structural equations modeling (MSGEM) was performed in Mplus (version 8.2; [26]) to examine the indirect effect of satisfaction with the supervisor on SP through perceived stress, and to examine differences across groups (gender, age, marital status, type of employment and education). This statistical strategy is preferred over general multivariate statistical analysis techniques, because possible differences in the mediating model can occur between the respective groups. MLR estimation was tested, because of non-normality patterns and missing values [27].

231

232

233

234

235

236

237

238

239

240

241

242

243

244

245

246

247

248

249

250

251

252

253

254

255

256

257

258

259

To assess model fit, the following fit indices with their respective thresholds [28] were used: $\chi^{2} / \mathrm{df}<3, \mathrm{CFI}>0.95, \mathrm{TLI}>0.95, \mathrm{RMSEA} \leq 0.06$ and $\mathrm{SRMR} \leq 0.08$. Significance of the equivalent testing process was verified by conducting a Chi-square difference test, using the SatorraBentler scaling correction [29].

\subsection{Satisfaction with supervisor invariance tests}

Before testing the theoretical model, confirmatory factor analysis (CFA) was performed to specify the model. First, an one-factor CFA model was tested. Results for the model showed poor fit $(\chi 2=600.412, \mathrm{df}=15, \chi 2 d f /=40.027, \mathrm{CFI}=0.946$, $\mathrm{TLI}=0.924, \mathrm{RMSEA}=0.109, S R M R=$ 0.025). Modification indices were then applied to improve model fit. The items 'satisfaction supervisor task conflicts' and 'satisfaction supervisor task division' were covaried. Also, items 'satisfaction supervisor appreciation' and 'satisfaction supervisor dealing with feelings', respectively 'satisfaction supervisor appreciation' with 'satisfaction supervisor task conflicts' were covaried. This is theoretically valid, since task conflicts stem from the task itself (compared to relational problems) and are expected to arise when tasks are inappropriately divided over workers. Workers may then end up with tasks that do not fit their skills and job responsibilities, or with tasks that are incompatible or too demanding, making them prone for task conflicts. Theoretical support for the covariation with supervisor appreciation is found in the distance between the work team and the supervisor. As correct appreciation (incorrect appreciation is associated with dissatisfaction) requires in-depth understanding of worker outputs and inputs, close monitoring by the supervisor reduces the prevalence of task conflicts and increases more active management of feelings of team members. Results for this model indicated a good fit $(-\chi 2=131.278, \mathrm{df}=12, \chi 2 d f /=10.939, \mathrm{CFI}=0.989, \mathrm{TLI}=0.981$, RMSEA $=0.055, S R M R=0.015)$. As shown in table 2 below, all standardized factor loadings were above 0.70 , ranging from 0.791 to 0.989 (all p's <.001). The AVE, Average Variance Extracted, was above the expected threshold (cut-off $=0.50$; [30]). The reliability values of the construct all measured above 0.90 .

Table 2. Measurement items, reliability and discriminant validity

\begin{tabular}{|c|c|c|c|c|c|c|c|c|c|c|c|c|}
\hline Variable & $\begin{array}{l}\text { General } \\
\text { model }\end{array}$ & Male & Female & Junior & Senior & Single & $\begin{array}{l}\text { Living } \\
\text { together }\end{array}$ & Married & Relationship & $\begin{array}{l}\text { White- } \\
\text { collar }\end{array}$ & $\begin{array}{l}\text { Blue- } \\
\text { collar }\end{array}$ & Government \\
\hline $\begin{array}{l}\text { Mutual } \\
\text { understanding }\end{array}$ & 0.902 & 0.900 & 0.900 & 0.902 & 0.900 & 0.897 & 0.901 & 0.989 & 0.917 & 0.899 & 0.850 & 0.909 \\
\hline
\end{tabular}




\begin{tabular}{|l|l|l|l|l|l|l|l|l|l|l|l|l|}
\hline $\begin{array}{l}\text { Dealing with } \\
\text { Feelings }\end{array}$ & 0.834 & 0.835 & 0.835 & 0.818 & 0.839 & 0.828 & 0.822 & 0.839 & 0.863 & 0.833 & 0.808 & 0.845 \\
\hline Appreciation & 0.850 & 0.850 & 0.850 & 0.827 & 0.857 & 0.807 & 0.843 & 0.868 & 0.851 & 0.853 & 0.791 & 0.858 \\
\hline Task conflict & 0.844 & 0.846 & 0.846 & 0.822 & 0.853 & 0.850 & 0.838 & 0.847 & 0.879 & 0.844 & 0.857 & 0.847 \\
\hline Task division & 0.820 & 0.822 & 0.822 & 0.807 & 0.825 & 0.806 & 0.811 & 0.828 & 0.825 & 0.822 & 0.846 & 0.808 \\
\hline $\begin{array}{l}\text { General } \\
\text { supervisor } \\
\text { satisfaction }\end{array}$ & 0.887 & 0.887 & 0.887 & 0.901 & 0.883 & 0.879 & 0.899 & 0.885 & 0.869 & 0.892 & 0.850 & 0.880 \\
\hline AVE & 0.734 & 0.735 & 0.735 & 0.718 & 0.739 & 0.714 & 0.728 & 0.770 & 0.753 & & 0.736 & 0.696 \\
\hline $\boldsymbol{\alpha}$ & 0.943 & 0.943 & 0.943 & 0.938 & 0.944 & 0.937 & 0.941 & 0.952 & 0.948 & 0.943 & 0.932 & 0.944 \\
\hline
\end{tabular}

Note: $\mathrm{AVE}=$ Average Variance Extracted.

261

262 In the second step, data was split into subgroups (e.g. male-only, female-only; single-only, married-only) to determine whether the socio-demographic characteristics affected the measurement model. Following Brown [28], we then subsequently performed three tests to validate measurement invariance for all demographic- grouping variables (gender, age, marital status, type of employment and education). Model comparison was done by using $\Delta \mathrm{CFI}$ and $\Delta \chi 2$.

In the initial step, configural equivalence was established, indicating an identical structure and patterns of factor loadings across groups. Second, a test was performed for metric equivalence, i.e. equal factor loadings across groups. In the third step, scalar measurement equivalence was tested, indicating that individuals from different groups gave same response to the latent construct 'Satisfaction with supervisor'.

273 The fit results of the one-factor model for the subsamples (single groups) and the fit results of the three levels of measurement equivalence are shown in table 3 . The fit indices for the subsamples of each socio-demographic characteristics demonstrated acceptable to good fit. Fit for single employees (marital status), however, was not good (RMSEA $=0.103$ ).

277 Lastly, to validate the measurement model a $\chi 2$ difference test was performed, using the Satorra-Bentler scaling correction [29]. Results from table 3 indicate that scalar measurement equivalence model was significant better than the configural and metric equivalence for gender and education group. 'PhD group' and 'Others' were not included in the analysis since their group size was marginally small (equal to 0). A full score comparability was thus plausible. Metric equivalence was established for marital status and type of employment. Finally, a similar model to the measurement invariance model was estimated, but paths were added between the satisfaction with supervisor, prevalence of stress and SP, including constraints of the paths (being equal across subgroups). To test for moderation, the latter model, i.e. all paths were constrained to be equal across groups, was compared to the unconstrained model where paths were not constrained to be equal across groups.

To evaluate invariance across education, respondents were divided into four groups: basic education, secondary education, Bachelor, Master. $\mathrm{PhD}$ and other degrees were not included, because of their marginal sample size. All invariance models were supported by the fit indices. Measurement invariance up to scalar equivalence is assumed across levels of education, supported by significant improvement of the model fit $(S-B \chi 2=20.242, p=0.163$ ) (Table 3-). 
293 To evaluate invariance across employment groups, white-collar, blue-collar and 294 governmental employees were split in three subgroups. Metric equivalence is assumed (S-B $295 \chi 2=20.239, \mathrm{p}=0.063)$, since scalar equivalence model did not significantly improve in fit.

296 A similar procedure was applied for marital status. Four groups were identified as subgroups: 297 single employees, employees living together, married employees and employees in relation 298 but not living together. Metric equivalence had a significant better fit than configural equivalence ( $\mathrm{S}-\mathrm{B} \chi 2=23.651, \mathrm{p}=0.167)$. Scalar equivalence model did not improve in fit.

300 The age of employees was divided into two subgroups, considering employees with an age 301 older than 35 years as being 'seniors', and employees younger or equal to 35 years as being 302 'juniors'. Metric equivalence is assumed ( $\mathrm{S}-\mathrm{B} \chi 2=5.420, \mathrm{p}=0.491$ ), indicating a significant 303 better fit than configural equivalence. Again, scalar equivalence did not improve in fit.

304 Lastly, using the same method, model was evaluated across gender groups with male and female employees, assuming scalar equivalence ( $\mathrm{S}-\mathrm{B} \chi 2=5.491, \mathrm{p}=0.483)$.

307 Table 3. Model fit indices measurement invariance equivalence process

\begin{tabular}{|c|c|c|c|c|c|c|c|c|c|c|c|}
\hline Variable & $\mathrm{M}$ & CFA & $\chi^{2}$ & $\mathrm{df}$ & CFI & TLI & RMSEA & SRMR & $\Delta \mathrm{CFI}$ & $\Delta \chi^{2 * *}$ & $\Delta \mathrm{df}$ \\
\hline \multirow[t]{8}{*}{ Education } & & Secundary & 13.247 & 6 & 0.995 & 0.989 & $0.044^{* *}$ & 0.009 & - & - & - \\
\hline & & Bachelor & 41.941 & 6 & 0.989 & 0.973 & $0.073^{*}$ & 0.012 & - & - & - \\
\hline & & Master & 35.787 & 6 & 0.993 & 0.981 & $0.062^{* *}$ & 0.01 & - & - & - \\
\hline & & Basic & 22.41 & 6 & 0.886 & 0.715 & $0.331^{*}$ & 0.043 & - & - & - \\
\hline & 1 & $\begin{array}{l}\text { Congifural } \\
\text { equivalence }\end{array}$ & 149.779 & 39 & 0.989 & 0.983 & $0.061^{*}$ & 0.025 & - & - & - \\
\hline & 2 & $\begin{array}{l}\text { Metric } \\
\text { equivalence }\end{array}$ & 176.436 & 57 & 0.988 & 0.987 & $0.052^{* *}$ & 0.035 & $\begin{array}{c}- \\
0.001 \\
\end{array}$ & 26.657 & 18 \\
\hline & 3 & $\begin{array}{l}\begin{array}{l}\text { Scalar } \\
\text { equivalence }\end{array} \\
\end{array}$ & 185.489 & 72 & 0.988 & 0.990 & $0.045^{* *}$ & 0.038 & 0.003 & 9.053 & 15 \\
\hline & 4 & MG MSEM $^{3}$ & 159.245 & 48 & 0.988 & 0.986 & $0.043^{* *}$ & 0.020 & - & - & - \\
\hline \multirow[t]{6}{*}{ Employment } & & White-collar & 51.119 & 6 & 0.993 & 0.981 & $0.059^{* *}$ & 0.009 & - & - & - \\
\hline & & Blue-collar & 14.123 & 6 & 0.98 & 0.951 & $0.091^{* *}$ & 0.015 & - & - & - \\
\hline & & Government & 23.567 & 6 & 0.994 & 0.984 & $0.057^{* *}$ & 0.01 & - & - & - \\
\hline & 1 & $\begin{array}{l}\text { Configural } \\
\text { equivalence }\end{array}$ & 121.054 & 28 & 0.990 & 0.984 & $0.056^{* *}$ & 0.012 & - & - & - \\
\hline & 2 & $\begin{array}{l}\text { Metric } \\
\text { equivalence }\end{array}$ & 145.984 & 40 & 0.988 & 0.987 & $0.05^{* *}$ & 0.035 & 0.002 & 24.930 & 12 \\
\hline & & $\begin{array}{l}\text { Scalar } \\
\text { equivalence }\end{array}$ & 166.037 & 50 & 0.987 & 0.099 & $0.046^{* *}$ & 0.042 & 0.001 & 20.053 & 10 \\
\hline \multirow[t]{8}{*}{ Marital status } & & Single & 36.156 & 6 & 0.98 & 0.95 & $0.103^{*}$ & 0.016 & - & - & - \\
\hline & & Living together & 18.395 & 6 & 0.995 & 0.988 & $0.051^{* *}$ & 0.009 & - & - & - \\
\hline & & Married & 47.874 & 6 & 0.991 & 0.978 & $0.062^{* *}$ & 0.011 & - & - & - \\
\hline & & Relationship & 4.598 & 6 & 1 & 1 & $0.00^{* *}$ & 0.008 & - & - & - \\
\hline & 1 & $\begin{array}{l}\text { Configural } \\
\text { equivalence }\end{array}$ & 154.375 & 39 & 0.988 & 0.982 & $0.06^{*}$ & 0.016 & - & - & - \\
\hline & 2 & $\begin{array}{l}\text { Metric } \\
\text { equivalence }\end{array}$ & 187.042 & 57 & 0.987 & 0.986 & $0.053^{* *}$ & 0.037 & $\begin{array}{c}- \\
0.001 \\
\end{array}$ & 32.667 & 18 \\
\hline & 3 & $\begin{array}{l}\text { Scalar } \\
\text { equivalence }\end{array}$ & 210.037 & 72 & 0.986 & 0.989 & $0.049^{* *}$ & 0.033 & $\begin{array}{c}- \\
0.001 \\
\end{array}$ & 22.995 & 15 \\
\hline & & MG MSEM & 269.31 & 97 & 0.987 & 0.985 & $0.047^{* *}$ & 0.031 & - & - & - \\
\hline \multirow[t]{3}{*}{ Age } & & Junior & 29.029 & 6 & 0.99 & 0.976 & $0.070^{* *}$ & 0.013 & - & - & - \\
\hline & & Senior $^{2}$ & 61.066 & 6 & 0.992 & 0.98 & $0.061^{* *}$ & 0.009 & - & - & - \\
\hline & 1 & $\begin{array}{l}\text { Configural } \\
\text { equivalence }\end{array}$ & 118.200 & 17 & 0.990 & 0.982 & $0.061^{*}$ & 0.013 & - & - & - \\
\hline
\end{tabular}




\begin{tabular}{|c|c|c|c|c|c|c|c|c|c|c|c|}
\hline & 2 & $\begin{array}{l}\text { Metric } \\
\text { equivalence }\end{array}$ & 129.501 & 23 & 0.989 & 0.986 & $0.053^{* *}$ & 0.020 & $\begin{array}{c}- \\
0.001\end{array}$ & 11.301 & 6 \\
\hline & 3 & $\begin{array}{l}\text { Scalar } \\
\text { equivalence }\end{array}$ & 143.147 & 28 & 0.988 & 0.987 & $0.05^{* *}$ & 0.023 & $\begin{array}{c}- \\
0.001 \\
\end{array}$ & 13.646 & 5 \\
\hline & & MG MSEM & 278.688 & 59 & 0.984 & 0.98 & $0.048^{* *}$ & 0.03 & - & - & - \\
\hline \multirow[t]{6}{*}{ Gender } & & Male & 36.895 & 6 & 0.994 & 0.984 & 0.053 & 0.01 & - & - & - \\
\hline & & Female & 69.345 & 6 & 0.986 & 0.966 & $0.085^{*}$ & 0.013 & - & - & - \\
\hline & 1 & $\begin{array}{l}\text { Configural } \\
\text { equivalence }\end{array}$ & 143.112 & 17 & 0.987 & 0.976 & $0.068^{*}$ & 0.015 & - & - & - \\
\hline & 2 & $\begin{array}{l}\text { Metric } \\
\text { equivalence }\end{array}$ & 156.537 & 22 & 0.986 & 0.981 & $0.061^{*}$ & 0.016 & $\begin{array}{c}- \\
0.001 \\
\end{array}$ & 13.425 & 5 \\
\hline & 3 & $\begin{array}{l}\text { Scalar } \\
\text { equivalence }\end{array}$ & 150.148 & 28 & 0.987 & 0.986 & $0.052^{* *}$ & 0.019 & 0.001 & -6.389 & 6 \\
\hline & & MGSEM & 213.151 & 48 & 0.987 & 0.984 & $0.046^{* *}$ & 0.018 & - & - & - \\
\hline
\end{tabular}

NOTE: ${ }^{*} \mathrm{p}<0.05,{ }^{* *} \mathrm{p}>0.05$

Note: only configural, metric, scalar and MGSEM are represented.

*** Not adjusted, Satorra-Bentler (2001) Scaled Difference Chi-Square Test is represented in table 4.

${ }^{2}$ Cut-off value is 35 (more than), ${ }^{3}$ Modified SEM is presented. Comparison done with unconstrained model

309 Table 4. Satorra-Bentler Scaled $\chi 2$ Difference test

\begin{tabular}{|c|c|c|c|c|c|c|c|c|c|c|}
\hline Variable & Level & $\mathrm{C} 1$ & $\mathrm{C} 0$ & D1 & D0 & F1 & F0 & $\begin{array}{l}\text { Satorra- } \\
\text { Bentler } \\
\text { Scaled } \chi 2\end{array}$ & $\mathrm{df}$ & $\mathrm{p}$-value \\
\hline \multirow[t]{3}{*}{ Gender } & $\begin{array}{l}\text { Metric vs } \\
\text { configural }\end{array}$ & 1.3123 & 1.4058 & 22 & 17 & 156.537 & 143.112 & 4.260514381 & 5 & 0.513 \\
\hline & $\begin{array}{l}\text { Scalar vs } \\
\text { metric }\end{array}$ & 1.4375 & 1.3123 & 28 & 22 & 150.148 & 156.537 & 5.491104048 & 6 & 0.483 \\
\hline & MG SEM & 1.2472 & 1.2633 & 51 & 48 & 219.12 & 213.151 & 4.054977466 & 3 & 0.256 \\
\hline \multirow[t]{2}{*}{ Education } & $\begin{array}{l}\text { Metric vs } \\
\text { configural }\end{array}$ & 1.1706 & 1.2894 & 57 & 39 & 176.436 & 149.779 & 14.68565375 & 18 & 0.683 \\
\hline & $\begin{array}{l}\text { Scalar vs } \\
\text { metric }\end{array}$ & 1.3189 & 1.1706 & 72 & 57 & 185.489 & 176.436 & 20.24258967 & 15 & 0.163 \\
\hline \multirow[t]{4}{*}{ Employment } & $\begin{array}{l}\text { Metric vs } \\
\text { configural }\end{array}$ & 1.2607 & 1.3408 & 40 & 28 & 145.984 & 121.054 & 20.23917452 & 12 & 0.063 \\
\hline & $\begin{array}{l}\text { Scalar vs } \\
\text { metric }\end{array}$ & 1.4166 & 1.2607 & 50 & 40 & 166.037 & 145.984 & 25.07890668 & 10 & 0.005 \\
\hline & MG SEM & 1.521 & 1.1638 & 76 & 70 & 224.098 & 211.763 & 16.59594701 & 6 & 0.011 \\
\hline & $\begin{array}{l}\text { MG SEM } \\
12\end{array}$ & 1.2031 & 1.2127 & 45 & 43 & 172.007 & 168.607 & 2.48009712 & 2 & 0.289 \\
\hline \multirow[t]{3}{*}{$\begin{array}{l}\text { Marital } \\
\text { status }\end{array}$} & $\begin{array}{l}\text { Metric vs } \\
\text { configural }\end{array}$ & 1.2251 & 1.3322 & 57 & 39 & 187.042 & 154.375 & 23.65115473 & 18 & 0.167 \\
\hline & $\begin{array}{l}\text { Scalar vs } \\
\text { metric }\end{array}$ & 1.3526 & 1.2251 & 72 & 57 & 210.037 & 187.042 & 29.91175875 & 15 & 0.012 \\
\hline & MG SEM & 1.1377 & 1.1508 & 76 & 70 & 228.035 & 223.427 & 2.351209538 & 6 & 0.885 \\
\hline \multirow[t]{3}{*}{ Age } & $\begin{array}{l}\text { Metric vs } \\
\text { configural }\end{array}$ & 1.2854 & 1.3589 & 23 & 17 & 129.501 & 118.2 & 5.4204199997 & 6 & 0.491 \\
\hline & $\begin{array}{l}\text { Scalar vs } \\
\text { metric }\end{array}$ & 1.3818 & 1.2854 & 28 & 23 & 143.147 & 129.501 & 17.17031141 & 5 & 0.004 \\
\hline & MG SEM & 1.1204 & 1.126 & 62 & 59 & 280.324 & 278.688 & 0.269554177 & 3 & 0.966 \\
\hline
\end{tabular}

NOTE: ${ }^{2}$ basis, secondary, PhD and other degrees were excluded from the analysis

\section{4. Results}

\section{4.1 Descriptives and bivariate analyses}


Table 5 indicates SP to be highly prevalent in the Belgian sample, with a clear majority of respondents admitting to have done SP themselves in the past 12 months. Adding those that have seen direct colleagues do SP, 8 out of 10 respondents have been in close contact with SP.

\section{Table 5. Prevalence of Sickness Presenteeism.}

\begin{tabular}{|l|l|l|}
\hline Answer & Number & Percentage \\
\hline Done SP in the past 12 months & 2043 & $62.4 \%$ \\
\hline $\begin{array}{l}\text { Not done SP, but seen SP in the past 12 } \\
\text { months }\end{array}$ & 609 & $18.6 \%$ \\
\hline $\begin{array}{l}\text { Not done SP, but heard about SP in the } \\
\text { past 12 months }\end{array}$ & 160 & $4.9 \%$ \\
\hline $\begin{array}{l}\text { Not done, seen or heard about SP in the } \\
\text { past 12 months }\end{array}$ & 462 & $14.1 \%$ \\
\hline
\end{tabular}

Note: $\mathrm{SP}=$ Sickness Presenteeism

A $\chi^{2}$-test of independence was performed comparing the frequency of SP in men and women. A significant interaction was found $\chi^{2}(3, \mathrm{~N}=3263)=70.75, \mathrm{p}<0.001$. Women were far more likely to admit having done SP $(69.8 \%)$ than men (56.6\%). Men also reported more often that they were not in any way confronted with SP over the past 12 months (17.8\%) than women (9.5\%). Also age was found to impact SP. Dividing respondents in two age groups below and above 35, shows older workers significantly less reporting having done SP themselves (59.4\%) compared to younger workers $(71.9 \%), \chi^{2}(3, \mathrm{~N}=3272)=48.69, \mathrm{p}<0.001$.

A $\chi^{2}$-test of independence was performed to examine the relation between SP and educational level. The relation between these variables was not significant, $\chi^{2}(15, \mathrm{~N}=3268)=25.23, \mathrm{p}=$ 0.06. Higher levels of education thus do not seem to lower SP. Also the relation between SP and type of employment was not significant, $\chi^{2}(6, \mathrm{~N}=3256)=4.39, \mathrm{p}=0.62$, showing civil servants and blue- and white-collar workers equally likely to do SP. Finally, also the relation between SP and relationship status (single versus non single) was not significant, $\chi^{2}(3, \mathrm{~N}=$ $3263)=3.45, \mathrm{p}=0.33$

Finally, we analyzed the effects of satisfaction with various life aspects on doing SP, of which the results are summarized in table 6.

Table 6. The relation between satisfaction with life aspects and SP.

\begin{tabular}{|l|l|l|l|l|l|l|l|}
\hline Satisfaction with: & \multicolumn{2}{|l|}{ Done SP } & \multicolumn{2}{l|}{ Not done SP } & $\mathrm{t}$ & Sig. & Cohen's d \\
\hline & $\mathrm{M}$ & $\mathrm{SD}$ & $\mathrm{M}$ & $\mathrm{SD}$ & & & \\
\hline Your job in general & 7.21 & 1.63 & 7.51 & 1.54 & $\mathrm{t}(2698)=5.18$ & $\mathrm{p}<0.001$ & $\mathrm{~d}=0.19$ \\
\hline $\begin{array}{l}\text { Number of actual } \\
\text { working hours }\end{array}$ & 6.74 & 2.28 & 7.29 & 1.96 & $\mathrm{t}(2979)=7.35$ & $\mathrm{p}<0.001$ & $\mathrm{~d}=0.26$ \\
\hline $\begin{array}{l}\text { Quality of work you can } \\
\text { deliver }\end{array}$ & 6.68 & 2.01 & 7.22 & 1.74 & $\mathrm{t}(2868)=8.13$ & $\mathrm{p}<0.001$ & $\mathrm{~d}=0.29$ \\
\hline $\begin{array}{l}\text { Your pay (including } \\
\text { benefits) }\end{array}$ & 6.81 & 1.98 & 7.31 & 1.74 & $\mathrm{t}(2830)=7.47$ & $\mathrm{p}<0.001$ & $\mathrm{~d}=0.27$ \\
\hline
\end{tabular}




\begin{tabular}{|l|l|l|l|l|l|l|l|}
\hline $\begin{array}{l}\text { Number of vacation } \\
\text { days }\end{array}$ & 7.46 & 2.15 & 7.81 & 1.91 & $\mathrm{t}(2823)=4.71$ & $\mathrm{p}<0.001$ & $\mathrm{~d}=0.17$ \\
\hline Your life in general & 7.40 & 1.50 & 7.75 & 1.32 & $\mathrm{t}(2838)=6.91$ & $\mathrm{p}<0.001$ & $\mathrm{~d}=0.25$ \\
\hline Your health & 7.09 & 1.74 & 7.69 & 1.43 & $\mathrm{t}(2958)=10.61$ & $\mathrm{p}<0.001$ & $\mathrm{~d}=0.37$ \\
\hline $\begin{array}{l}\text { Your monthly family } \\
\text { budget }\end{array}$ & 6.87 & 1.98 & 7.48 & 1.72 & $\mathrm{t}(2810)=9.14$ & $\mathrm{p}<0.001$ & $\mathrm{~d}=0.33$ \\
\hline Your savings & 6.06 & 2.48 & 6.71 & 2.29 & $\mathrm{t}(2731)=7.58$ & $\mathrm{p}<0.001$ & $\mathrm{~d}=0.27$ \\
\hline
\end{tabular}

After establishing the invariance measurement model, our analysis proceeded with testing the structural model and the hypotheses. Table 4 provides an overview of the significance tests for multigroup comparisons. To test for socio-demographic moderation, the SatorraBentler scaled $\chi 2$ difference test was conducted.

For the socio-demographic variables gender, age and marital status the fully constrained model did not improve in fit compared to the unconstrained model, indicating there was no moderation effect found. For type of employment and education the model was modified.

\subsubsection{Gender}

351 Results show that satisfaction with the supervisor has a negative direct effect on prevalence 352 of stress $(\beta=-0.323, \mathrm{SE}=0.022, \mathrm{p}<0.001)$ for male $(\mathrm{n}=1826)$ and female- $(\mathrm{n}=1439)$ respondents $353(\beta=-0.343, \mathrm{SE}=0.024, \mathrm{p}<.001)$. Prevalence of stress also had a positive direct effect on SP for male $(\beta=0.215, \mathrm{SE}=0.024, \mathrm{p}<0.001)$ and female respondents $(\beta=0.179, \mathrm{SE}=0.027, \mathrm{p}<0.001)$. Lastly, satisfaction with supervisor had a direct marginal negative effect on SP $(\beta=-0.073, \mathrm{SE}=0.025$, $\mathrm{p}=0.004)$. Indirect effects are found for female and male employees between satisfaction with supervisor and SP via prevalence of stress (male: $\beta=-0.034$, $\mathrm{SE}=0.005, \mathrm{p}<0.001$; female: $\beta=-0.028$, $\mathrm{SE}=0.005, \mathrm{p}<0.001)$. However, gender moderation was not significant $(\mathrm{S}-\mathrm{B} \chi 2=4.055, \mathrm{p}=0.256$ ) and hypothesis $4 \mathrm{~b}$ was therefore rejected.

Results show that for younger respondents $(n=2572)$, age less than 35 , satisfaction with supervisor has a direct negative effect on prevalence of stress $(\beta=-0.335, \mathrm{SE}=0.038, \mathrm{p}<0.001)$. Also, prevalence of stress has a moderate direct effect on SP $(\beta=0.205, \mathrm{SE}=0.020, \mathrm{p}<0.001)$. No significant effect was found for satisfaction with supervisor on SP $(\beta=-0.053$, SE $=0.041$, $\mathrm{p}=0.167)$.

For senior employees $(n=3272)$, satisfaction with supervisor has a direct negative effect on prevalence of stress $(\beta=-0.332, \mathrm{SE}=0.019, \mathrm{p}<0.001)$. Also, prevalence of stress had a direct effect on SP $(\beta=0.206, \mathrm{SE}=0.020, \mathrm{p}<0.001)$. Significant effect was found for satisfaction with supervisor on SP $(\beta=-0.061, \mathrm{SE}=0.021, \mathrm{p}=0.003)$. -For both groups, there was an indirect effect of satisfaction with supervisor on SP via prevalence of stress $(\beta=-0.031, \mathrm{SE}=0.007, \mathrm{p}<0.001$ (junior), $\beta=-0.034, \mathrm{SE}=0.004, \mathrm{p}<0.001$ (senior)). No significant differences are found between junior and senior employees. 
An examination of differences in adjusted $\chi 2$ between the model and the full constrained model, indicating that there was no age moderation (S-B $\chi 2=0.269, \mathrm{p}=0.966$ ) and rejecting hypothesis $5 b$.

\subsubsection{Education}

Since the subgroups have large differences in group size, adjustments have been made to conduct the analysis. A multi-group comparison between bachelor and master holders was therefore preferred. Basic, secondary, $\mathrm{PhD}$ and other degrees were not included in the analysis.

Results for Bachelor holders ( $\mathrm{n}=1140$ ) indicated that satisfaction with supervisor had a direct negative effect on prevalence of stress $(\beta=-0.377, \mathrm{SE}=0.028, \mathrm{p}<0.001)$. Prevalence of stress had a direct effect on SP $(\beta=0.215, \mathrm{SE}=0.030, \mathrm{p}<0.001)$. Satisfaction with supervisor showed a significant effect on SP $(\beta=-0.067, \mathrm{SE}=0.031, \mathrm{p}=0.034)$.

For master holders $(\mathrm{n}=1320)$, satisfaction with supervisor had a direct negative effect on prevalence of stress $(\beta=-0.288, \mathrm{SE}=0.027, \mathrm{p}<0.001)$. Prevalence of stress had a direct effect on SP $(\beta=0.206, \mathrm{SE}=0.07, \mathrm{p}<0.001)$. Also satisfaction with supervisor had a marginal negative effect on SP $(\beta=-0.081, \mathrm{SE}=0.028, \mathrm{p}=0.004)$. No results were obtained for other degrees, since their group sample size was marginal (basic education, $n=25$; secondary education, $n=625$ ).

Indirect effects were found between satisfactory with supervisor and SP via prevalence of stress for bachelor holders $(\beta=-0.039, \mathrm{SE}=0.006, \mathrm{p}<0.001)$ and master $(\beta=-0.029, \mathrm{SE}=0.005$, $\mathrm{p}<0.001$ ).- No significant differences appeared between the educational groups, indicating there was no education moderation (S-B $\chi 2=5.795, \mathrm{p}=0.112$ ).

\subsubsection{Marital Status}

Employees in a relationship was marginally smaller ( $n=166)$ compared to the other subgroups. Therefore, this subgroup was not included in the multi-group comparison.

For single employees $(n=476)$, satisfaction with supervisor had a significant direct negative effect on prevalence of stress $(\beta=-0.311, \mathrm{SE}=0.042, \mathrm{p}<0.001)$. Prevalence of stress had a direct effect on SP $(\beta=0.244, \mathrm{SE}=0.045, \mathrm{p}<0.001)$. Satisfaction with supervisor had a non-significant negative direct effect on SP $(\beta=-0.049, \mathrm{SE}=0.045, \mathrm{p}=0.295)$.

For employees living together $(\mathrm{n}=791)$, satisfaction with supervisor had a direct negative effect on prevalence of stress $(\beta=-0.316, \mathrm{SE}=0.036, \mathrm{p}<0.001)$. Prevalence of stress had a direct effect on SP $(\beta=0.231, \mathrm{SE}=0.036, \mathrm{p}<0.001)$. There was no significant effect of satisfaction with supervisor on $\mathrm{SP}(\beta=-0.029, \mathrm{SE}=0.038, \mathrm{p}=0.438)$.

Results for married employees $(n=1830)$ indicated that satisfaction with supervisor had a direct negative effect on prevalence of stress $(\beta=-0.349, \mathrm{SE}=0.023, \mathrm{p}<0.001)$. Prevalence of stress had a direct effect on SP $(\beta=0.185, \mathrm{SE}=0.024, \mathrm{p}<0.001)$. Satisfaction with supervisor showed a significant effect on SP $(\beta=-0.064, \mathrm{SE}=0.025, \mathrm{p}=0.010)$. 

of stress for single employees $(\beta=-0.036, \mathrm{SE}=0.008, \mathrm{p}<0.001)$, employees living together $(\beta=-$ 0.032 , SE=0.005, $\mathrm{p}<0.001)$, married employees $(\beta=-0.035, \mathrm{SE}=0.007, \mathrm{p}<0.001)$.

412 Similar to the other steps, we checked whether the model significantly improved from the 413 unconstrained model. Fit results indicated that there was no marital status moderation (S-B $414 \chi 2=3.403, \mathrm{p}=0.946)$, rejecting Hypothesis 8.

Table 7. Moderation overview

\begin{tabular}{|l|l|l|l|l|}
\hline Variable & $\begin{array}{l}\text { Satisfaction with } \\
\text { supervisor }->\text { stress }\end{array}$ & Stress $->\mathrm{SP}$ & $\begin{array}{l}\text { Satisfaction with } \\
\text { supervisor } \rightarrow \mathrm{SP} \\
\text { (indirect) }\end{array}$ & $\begin{array}{l}\text { Satisfaction with } \\
\text { supervisor }->\mathrm{SP} \\
\text { (direct) }\end{array}$ \\
\hline Male & $\beta=-0.323, \mathrm{p}<0.001$ & $\beta=0.215, \mathrm{p}<0.001$ & $\beta=-0.034, \mathrm{p}<0.001$ & \\
\hline Female & $\beta=-0.343, \mathrm{p}<0.001$ & $\beta=0.179, \mathrm{p}<0.001$ & $\beta=-0.028, \mathrm{p}<0.001$ & \\
\hline Junior & $\beta=-0.335, \mathrm{p}<0.001$ & $\beta=0.205, \mathrm{p}<0.001$ & $\beta=-0.031, \mathrm{p}<0.001$ & $\beta=-0.053, \mathrm{p}=0.167$ \\
\hline Senior & $\beta=-0.332, \mathrm{p}<0.001$ & $\beta=0.206, \mathrm{p}<0.001$ & $\beta=-0.034, \mathrm{p}<0.001$ & $\beta=-0.061, \mathrm{p}=0.003$ \\
\hline Bachelor & $\beta=-0.377, \mathrm{p}<0.001$ & $\beta=0.215, \mathrm{p}<0.001$ & $\beta=-0.039, \mathrm{p}<0.001$ & $\beta=-0.215, \mathrm{p}<0.001$ \\
\hline Master & $\beta=-0.288, \mathrm{p}<0.001$ & $\beta=0.206, \mathrm{p}<0.001$ & $\beta=-0.029, \mathrm{p}<0.001$ & $\beta=-0.081, \mathrm{p}=0.004$ \\
\hline Single & $\beta=-0.311, \mathrm{p}<0.001$ & $\beta=0.244, \mathrm{p}<0.001$ & $\beta=-0.036, \mathrm{p}<0.001$ & $\beta=-0.049, \mathrm{p}=0.295$ \\
\hline Living together & $\beta=-0.316, \mathrm{p}<0.001$ & $\beta=0.231, \mathrm{p}<0.001$ & $\beta=-0.032, \mathrm{p}<0.001$ & $\beta=-0.029, \mathrm{p}=0.438$ \\
\hline Married & $\beta=-0.349, \mathrm{p}<0.001$ & $\beta=0.185, \mathrm{p}<0.001$ & $\beta=-0.035, \mathrm{p}<0.001$ & $\beta=-0.064, \mathrm{p}=0.010$ \\
\hline
\end{tabular}

416

\subsection{The mediation model}

Next, a full mediation path analysis was done for all employees. All fit indices met the thresholds, indicating a good fit $\left(x^{2}=93.753, \mathrm{CFI}=982\right.$, TLI=0.969, RMSEA=0.039, SRMR=0.013).

Standardized estimates are presented in Figure 1. Satisfaction with supervisor is negatively related to prevalence of stress $(\beta=-0.340, \mathrm{SE}=0.016, \mathrm{p}<0.001)$. Prevalence of stress is positively related to $\mathrm{SP}(\beta=0.256, \mathrm{SE}=0.022, \mathrm{p}<0.001)$. Also, Satisfaction with supervisor is negatively related to SP $(\beta=-0.088, \mathrm{SE}=0.024, \mathrm{p}<0.001)$. This effect is, however, marginal. The indirect effect is significant, indicating that satisfaction with supervisor is negatively related to SP via prevalence of stress $(\beta=-0.045, \mathrm{SE}=0.005, \mathrm{p}<0.001$; total effect: $\beta=-0.090, \mathrm{SE}=0.012, \mathrm{p}<0.001)$.

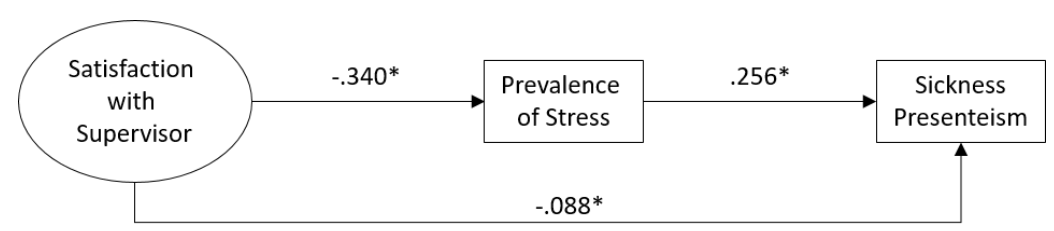

Figure $1, * p<.001$

\section{Discussion and future research}

431 One of the main findings of this research is that SP is quite prevalent in the Belgian workforce, with $62 \%$ of FTEs in our study admitting that they have done SP at least once in the past 12 months. Moreover, only $14 \%$ did not see, experience or hear about SP, making it a priority for 
both academics and practitioners. Previous research has indicated that SP may lead to higher levels of SA in the near future, increase the period of suboptimal production due to the prolonged recovery of the worker and cause healthy workers to be infected by the sick. Given the likelihood of these effects and the prevalence of SP in the sample, the potential costs for organizations are substantial enough to warrant an organizational policy on the matter.

Our full mediation path analysis shows that the prevalence of stress is positively related to SP and also mediates the relation between satisfaction with the supervisor and SP, supporting hypothesis $\mathrm{H}_{2}$ and $\mathrm{H}_{3}$. We also found a direct effect of satisfaction with the supervisor on SP, supporting $H_{1}$, but since this effect is marginal, it is claimed that stress is an important factor in the relationship. When workers are unhappy with how their supervisor deals with task conflicts, task division and feelings in the team, there is an increased probability that they will turn up at work sick. This may be due to a form of introjected regulation, believing that their presence is required in order not to leave the coworkers behind (with additional work) in the hands of a poor supervisor. Feelings of guilt may thus stimulate a worker to opt for SP rather than SA. With the recent and still ongoing trend of organizations to downsize staff numbers and continuous work intensification, this pressure is not unlikely. But the strong indirect effect of satisfaction with the supervisor on SP, via stress, suggests that there is also a clear individualistic effect, regardless of the effect on the coworkers. When poor supervision leads to stress, the perceived work pressure may drive workers to forfeit their SA and to show up at work sick, in order to avoid that work piles up even more. We thus mark that the risk of SP is especially high in workplace in which the behavior of the supervisor has a strong effect on stress levels, for example due to low levels of role clarity, and in which compensatory effects (like co-worker support or high levels of autonomy) are absent. Also, when sick workers opt for SP because they fear their work will remain undone because the healthy coworkers do not know how to do it, organizations preferring specialization over generalization may thus be more prone to SP.

Our analyses did not support our hypothesis that women would report less SP compared to men $\left(H_{4 a}\right)$, because of a greater likelihood to pursue healthy lifestyles. Women were significantly more likely to report SP in the past 12 months than men. This finding may be affected by the fact that men are more likely to take a macho perspective on sickness, believing one is never too sick to go to work. This may also explain why men significantly more often than women report that they did not see or hear about SP in their organization. It may thus be possible that women are referring to a range of male colleagues when they report having seen direct colleagues do SP, while these male colleagues consider themselves not sick and thus not reporting SP. The percentage of men doing SP may thus be underreported. Nevertheless, the findings crack down beliefs that women are always taking the more healthy decisions, with $70 \%$ of women doing SP. The rejection of gender as a moderator, rejecting hypothesis $H_{4 b}$ also marks that men and women are being similarly affected by the satisfaction with their supervisor and the prevalence of stress, in their decision to do SP. Our findings thus imply that also women are not immune to external factors stimulating them to believe going to work is mandatory, for one reason or another, even when sick. Organizational policies and future research should thus not neglect female workers in their attempts to reduce SP. 
Our findings do, on the other hand, support the hypothesis that senior workers would report less SP than junior workers $\left(H_{5 a}\right)$. Splitting the sample in age groups below and over 35, we found a strong significant difference between junior and senior workers in the expected direction. This finding may be driven by the fact that senior workers have already made a career and therefore feel less forced to coming to work sick in order not to hamper their perceived promotion opportunities. However, while there is a strong difference between the groups, it is quite apparent that still almost 6 out of ten senior workers report having done SP. Thus, although younger workers are more likely to do SP, older workers should not be expected to always take the healthy decision. We also had to reject our hypothesis that age would moderate the relationship between satisfaction with the supervisor and SP ( $\left.\mathrm{H}_{5 b}\right)$. This implies that senior workers are not necessarily more immune to poor supervision than the juniors. One possible explanation is the inclusion of the worker's satisfaction with the appreciation that the supervisor shows for the work being done, as part of the satisfaction scale. While juniors may require more directing from the supervisor than the seniors, (lack of) appreciation has been found to affect workers at all ages and hierarchical positions. Moreover, improper distribution of tasks will affect workers with various levels of expertise, especially in work environments with lower levels of autonomy, making these workers prone to stress and therefore to SP.

We also did not find support for our hypothesis that higher educated workers would report less SP than lower educated workers $\left(H_{6}\right)$. We assumed that higher education would provide workers with more options on the labor market, making them less inclined to sacrifice health for employment reasons. This finding may imply that both higher and lower educated workers may base their decision between SA and SP on the short term and limited to their current organization. When workers, e.g., are experiencing a comfort zone - they want to keep working in their current organization - labor market opportunities become irrelevant in the equation. And if leaving is not an option, the effect of SA may have a similar effect on career opportunities for both higher and lower educated workers. Future research should therefore take the comfort zone of the worker into account when analyzing SP decisions. We did not find a moderation effect for education. This indicates that supervisor support is at least equally important in the SP-decision for master and bachelor diploma holders. Due to the small group sizes for the lower educational levels, we were however not able to test the full range of our hypothesis.

There was also no support for our hypothesis that singles would report more SP than nonsingles $\left(H_{8}\right)$. This may due to our research design, as we did not include questions on the current living situation of the single. When single workers e.g., still live with their parents, the may not feel the pressure on their monthly budget as much as we expected they would. They may even be quite in line with the financial stability found among two-income married couples. Also, as we did not ask the married respondents whether their spouse obtained an income. It may thus be that married workers from one income families are prone to quite similar financial pressures as the single workers living on their own. Our hypothesis was thus narrowed to the effect of having a partner to rely on when sick or not. Our findings do not 
517 support the idea that knowing that there is someone to take care of you, would lower the

518 probability of SP.

519 Instead, it may be more relevant to consider the effect of a worker's satisfaction with his 520 financial situation on SP $\left(H_{7}\right)$. In support of our hypothesis, we found that satisfaction with 521 the monthly family budget differs significantly over workers doing and not doing SP. Based 522 on Cohen's d, it is even the second largest effect in the sample, after satisfaction with one's 523 health. We also found that satisfaction with savings and the monthly pay affect one's decision 524 between SA and SP, although the effect is slightly lower than for the monthly family budget. 525 This may provide support for our call to take the financial situation of the partner more 526 explicitly into account. While pay and savings were referring to the individual's personal 527 situation, the monthly family budget also can include the partner (if present). The higher means for both groups imply that having a partner providing a second wage has an effect on satisfaction levels and thus possibly on the SA and SP decision. Still, being critical about these findings, we do note that the effect size remains small to medium.

531 It is important to note that our findings differ slightly from those reported by Zhou et al [13]. 532 While these authors reported that social support from the supervisor could increase the productivity of the sick worker doing SP (studying what happens when the sick worker show up at work), our findings indicate that when support from the supervisor is felt by the worker (every day, also when not sick) the prevalence of SP is lower. Linking our findings to the Zhou et al [13] research, we may conclude that support from the supervisor makes it less likely that workers will show up sick, and will also increase their performance when they show up sick after all.

\section{Limitations}

To improve fit of the initial general factor structure for Satisfaction with Supervisor, modification indices were applied. In our study modification indices were theoretically sound. However, one must still be cautious when interpreting the results of this study. Since the factor structure yielded poor fit, using the confirmatory factor analysis technique, the psychometric validity and plausibility of the concept can be questioned. -Asparouhov and Muthén [31] stated that CFA are often used as explorative technique and a set of modifications are then implemented to improve fit. Exploratory factor analysis (ESEM) is then preferred, since misspecified loadings are directly detected.

Second, unequal group sizes can influence model fit [32]. According to Barret [32], SEM analysis should not be computed on group sizes $<200$. A possible alternative for the unequal groups is to regroup them. Specifically, a moderate difference is found for type of employment (i.e. small group of blue-collar employees), level of education (i.e. marginal group of employees holding a basic degree), and marital status (i.e. small group of employees in relationship). 
more mentally fatiguing jobs. Based on our sample, including only $5 \%$ of blue-collar workers, we suspect that physical workload was not widely dispersed and does not affect our data. However, the inclusion of physical workload as a variable in explaining SP is marked as a necessity in future studies on SP in more diverse physical employment settings.

\section{Policy implications}

Based on the high numbers of SP reported in this study, we advise organizations to draw up and communicate a clear policy on SP. Organizations can also use reoccurring events like announcements about flew epidemics in popular newspapers and television, to communicate and remind staff about the SP-policy, making the topic more alive in the company. A third possibility is the option of storytelling, whereby supervisors tell the story of workers who always took a rest when they were sick and where still easily promoted some years later. Finally, having an occupational physician send a sick workers home may also provide a clear signal to workers and work against peer pressure and macho culture to do SP.

\section{Conclusion}

Sickness presenteeism is highly prevalent in today's organisations and constitutes physical and mental health risks, demanding new policy measures from organizational and governmental decision makers. Dissatisfaction with supervisor support and the prevalence of stress are important predictors for sickness presenteeism.

\section{References}

[1] Hemp P. Presenteeism: At work - But out of it. Harv Bus Rev 2004;82:49-58.

[2] Bergström G, Bodin L, Hagberg J, Aronsson G, Josephson M. Sickness presenteeism today, sickness absenteeism tomorrow? A prospective study on sickness presenteeism and future sickness absenteeism. J Occup Environ Med. 2009;51:629-638.

[3] Johns G. Presenteeism in the workplace: A review and research agenda. J Org Beh 2010;31:519-542.

[4] Baker-McClearn D, Greasley K, Dale J, et al. Absence management and presenteeism: the pressures on employees to attend work and the impact of attendance on performance. Hum Resour Man J 2010;20:311-328.

[5] Grinyer A, Singleton V. Sickness absence as risk-taking behaviour: A study of organisational and cultural factors in the public sector. Health Risk Soc 2000;2:7-21. 
[6] Nagata T, Mori K, Ohtani M, et al. Total Health-Related Costs Due to Absenteeism, Presenteeism, and Medical and Pharmaceutical Expenses in Japanese Employers. J Occup Environ Med 2018,60(5):273-280.

[7] Leineweber C, Westerlund H, Hagberg J, et al. Sickness presenteeism among Swedish police officers. J Occup Rehabil 2011;21:17-22.

[8] Hansen C, Andersen J. Going ill to work - what personal circumstances, attitudes and work-related factors are associated with sickness presenteeism? Soc Sci Med 2008;67:956-964.

[9] Skagen K, Collins A. The consequences of sickness presenteeism on health and wellbeing over time: A systematic review. Soc Sci Med 2016;161:169-177.

[10] Lu L, Lin H, Cooper C. Unhealthy and present: motives and consequences of the act of presenteeism among Taiwanese employees. J Occup Health Psychol 2013;18:406-416.

[11] Gustafsson K, Marklund S. Consequences of sickness presence and sickness absence on health and work ability: a Swedish prospective cohort study. Int J Occup Med Environ Health 2011;24:153-165.

[12] Lu L, Peng S, Lin H, et al. Presenteeism and health over time among Chinese employees: The moderating role of self-efficacy. Work Stress 2014;28:165-178.

[13] Zhou Q, Martinez L, Ferreira A, et al. Supervisor support, role ambiguity and productivity associated with presenteeism: A longitudinal study. J Bus Res 2016;69:3380-3387.

[14] Thun S, Halsteinli V, Lovseth L. A study of unreasonable illegitimate tasks, administrative tasks, and sickness presenteeism amongst Norwegian physicians: an everyday struggle? BMC Health Serv Res 2018,18:407.

[15] Hobföll S. The influence of culture, community, and the nested self in the stress process: Advancing conservation of resources theory. Appl Psychol-Int Rev 2001;50:337-370.

[16] Demerouti E, Le Blanc P, Bakker A, et al. Present but sick: A three-wave study on job demands, presenteeism and burnout. Career Dev Int 2009;14: 50-68.

[17] Oldham G, Cummings A. Employee creativity: Personal and contextual factors at work. Acad Manage J 1996;39:607-634.

[18] Biron C, Brun J, Ivers H, et al. At work but ill: psychosocial work environment and wellbeing determinants of presenteeism propensity. J Public Ment Health 2006;5:26-37.

[19] Locke E, Latham G. A theory of goal setting and task motivation. Englewood: Prentice Hall, 1990. 
[20] Jian GW, Dalisay F. Talk matters at work : the effects of leader-member conversational quality and communication frequency on work role stressors. J Bus Commun 2018;55:483-500.

[21] Ek S. Gender differences in health information behaviour: A Finnish population-based survey. Health Promot Int 2015;30(3):736-745.

[22] Garcia-Cabrera AM, Lucia-Casademunt AM, Cuéllar-Molina D, et al. Negative workfamily/family-work spillover and well-being across Europe in the hospitality industry: The role of perceived supervisor support. Tourism Manage 2018;26:39-48.

[23] Blanchard K. Leading at a higher level. London: Prentice Hall, 2007.

[24] Aronsson G, Gustafsson K. Sickness presenteeism: Prevalence, attendance pressure factors, and an outline of a model for research. J Occup Environ Med 2005;47:958-966.

[25] McGregor A, Sharma R, Magee C, et al. Explaining variations in the findings of presenteeism research: A meta-analytic investigation into the moderating effects of construct operationalizations and chronic health. J Occup Health Psychol 2018;23(4):584-601.

[26] Muthén LK, Muthén BO. Mplus User's Guide. Los Angeles (CA): Muthén \& Muthén, 2017.

[27] Muthén, B. and Asparouhov, T. (2002). Using Mplus Monte Carlo simulations in practice: A note on non-normal missing data in latent variable models. Version 2, March 22, 2002.

[28] Brown TA. Confirmatory factor analysis for applied research. New York (NY): Guilford Publications; 2014.

[29] Satorra A, Bentler PM. Ensuring positiveness of the scaled difference chi-square test statistic. Psychometrika 2010;75:243-248.

[30] Fornell C, Larcker D. Evaluating structural equation models with unobservable variables and measurement error. J Mark Res 1981;188:39.

[31] Asparouhov T, Muthén B. Exploratory structural equation modelling. Struct Equ Modeling 2009;16:397-438.

[32] Barrett P. Structural equation modelling: Adjudging model fit. Pers Individ Diff 2007;42:815-824. 